\title{
The Development of Organizational and Management Structures in Small-scale and Mid-scale Entrepreneurship in the Czech Republic
}

\author{
Jan Váchal $^{1 *}$, Milan Talír ${ }^{1}$ \\ ${ }^{1}$ Institute of Technology and Business, Faculty of Corporate Strategy, Okružní 517/10, 37001 České \\ Budějovice, Czech Republic
}

\begin{abstract}
The business architecture, whose integral part is an organizational and management company structure, will be playing more important role in the future while pursuing its business goals. As a matter of fact, the organization and management of business processes that constitute its organizational and management structure demonstrate significant changes as a result of the changeable business environment. These issues are discussed in this article. The testing data set 381 SMEs (from which 114 were micro-enterprises, 141 small-scaled enterprises and 126 mid-scale enterprises, including without limitations enterprises from South Bohemian Region) analyzed applied organizational and management structures in separate scale categories of enterprises including degrees and stages of management. Pearson's chi-squared test was used as a statistical method; pvalue was employed to test zero and alternative hypotheses. SMEs manifested a transition from linear and line-staff structures to matrix and functional ones; mid-scale enterprises used strategic business units. Microenterprises and partly small-scale enterprises employed degree of management, mid-scale 3 and more degrees of management. The conclusion of the article specifies the estimated development of the organizational architecture in SMEs in the Czech Republic in relation to expected changes in the external business environment in particular.
\end{abstract}

Key words: organizational structure, management structure, levels of management, scope management

\section{Introduction}

In order to deal with the issue of organizational and management structures in small-scale and mid-scale enterprises (SMES), this topic needs to be anchored in the overall development of small-scale and mid-scale entrepreneurship in the world and the Czech Republic. Smallscale and mid-scale entrepreneurship thrived in the most of the ancient cultures. Until the Second World War, the then ČSR (Czechoslovak Republic) belonged to the most industrially

*Corresponding author: vachal@mail.vstecb.cz 
developed countries in the world. The vast majority of trade subjects, where vocational and business trades dominated, were no bigger than five workers. The social significance of small-scale entrepreneurship and its positive influence on the economy and welfare of the country was acknowledged no sooner than after the Second World War within the programme of the post war restoration of national economies. The development in the Czech Republic and other countries of the Central and Eastern Europe in particular was profoundly different from that of their western counterparts. The period after the Second World War saw a considerable decline. The winding-up of private SMES resulted in gaining a dominant position of large and state-owned enterprises that were established in an administrative way.

The important milestone in the development of the business environment on the market was marked with year 1989. Constitutional Act No. 100/1991 Sb. which granted equal rights to all kinds of ownership was enacted in 1991. The business sphere demonstrated an exponential increase. Only 19,000 enterprises were registered in 1989; on the other hand, year 2018 saw a tenfold increment. SMES got stable in the Czech Republic and became stabilizers of the national economy as it had been in other EU member states, and, they not only got into new sales markets, but also had to face competitors; all the same, they were at the same time supported by both - the state and the EU.

In regard to the development of organizational and management structures, these before the Second World War may be nowadays termed as linear, i.e. line-staff structures when applying directive and centrist management. It is mostly line-staff structures with department and profession specifications that developed after the Second World War. This, then innovative, development was discontinued by the decline and winding up of the predominating part of SMES in the Czech Republic. On the other hand, the world economy sees a rapid development of SMES mostly as a result of changes in their macro environment. Burns and Stalker [1] and other authors emphasize the relation between the organizational structure, changes in the external environment and efficiency of the organization. After 1989 the Czech Republic goes through a rapid development of all units of small-scale and midscale entrepreneurship (micro enterprises, small-scale enterprises and mid-scale enterprises) which means that the development of new organizational and management structures also takes place. Changes in the external environment of SMES occurring from the end of the last century require substantial changes in their current architecture [2]. Banner [3] argues that these changes mostly refer to organizational and management structures [4]. Friesen [5] specifies these factors that cause changes in organizational and management structures as general variables of organizational structures. Hodge, Anthony and Gales [6] define organizational structures as a means for classifying and coordinating the organization according to the kind of work, tasks, goals and processes.

O'Neal, Beauvais and Scholl [7] refer to conventional definitions of the following authors: Mintzberg [8-9], Katz and Kahn [10] and Burns and Stalker [1]. These authors define organizational structures as a stage of centralization of the decision-making process, establishment of rules, authority, communication and compensation, standardization of workflows and skills including control activities of the enterprise. Mintzberg [8-9] analyses the relations between the organizational structure and the age of the company, size, adopted strategy, available technologies, external environment and culture of the organization. Moreover, he, as one of the first authors, also points out the relationship between the organizational structure and corporate strategy. A similar opinion is expressed by Miller in his articles [11] where, apart from the relationship between the business organization and corporate strategy, he speaks about strategic goals. On the other hand, Friesen [5] entertain a different opinion on the definition of the organizational structure. They argue that the organizational structure is determined by the current life-cycle period in which the specific enterprise currently exists. As a matter of fact, some structures are laid down by the relevant legislation and local conventions such as Améba, virtual enterprise etc. 
The formal part of the organizational structure is usually implemented by organizational schemes, policies and procedures [8-9], assignment of competences, roles and responsibilities, management and control of formal communication mechanisms and human resources management [12]. Wang and Ahmed [13] refer to these elements as 'hard'. On the other hand, there are also 'soft' elements often referred to as informal structure including e.g. interpersonal relationships and relationships on the diagonal communication stage, which are not explicitly expressed in the organizational code of the enterprise. Hodge, Anthony and Gales [6] declare that the informal structure is not only a logical consequence of social networks and relationships between employees, which develop within the work process, but it can also develop as a result of a defective or ineffective formal structure. Wang and Ahmed [13] argue that what is tolerated is an inconsistency between the informal structure and formal organizational rules, relationships and standards and competency relations. A large number of authors $[4,5,2]$ nowadays point out that SMESs will have to be more flexible, adaptable, agile and integrating in regard to their competitiveness and effectiveness in the near future. Hunter [12] emphasizes the importance of innovations and he further argues that enterprises should continuously improve their technical equipment, work processes and inputs and outputs. He declares that the organizational structure needs to be sometimes changed in order to achieve new and progressive goals. As applied by analogy, Cooper [14] and Hunter [12] point out the importance of the implementation of new innovative business structures. In relation to ongoing changes in organizational structures, term de-structured forms of organizational structures including new, perspective structures such as network, process, cellular, quantum structures and organized design.

\section{Data and Methods}

The research was carried out on a selected data set of SMESs including without limitations enterprises from South Bohemian Region. The research started in 2016 and has been conducted until now. The data set contains 381 enterprises from which 114 are micro enterprises, 141 small-scale enterprises and 126 mid-scale enterprises. Test sample was set up in cooperation with the Czech Statistical Office to reflect the actual structure of the companies within South Bohemian region.

Two hypotheses were formulated: SMES.

H1: Linear and line-staff organizational and management structures predominate in

$\mathrm{H} 2$ : Single stage management system predominates in micro enterprises and small-scale enterprises; three and more management stages predominate in mid-scale enterprises.

Pearson's chi-squared test was used as a statistical method in order to determine the dependence / independence of the selected category variables (internal and external strategic analyses) for formulating corporate strategy.

The equation for Pearson's chi-square test of independence is as follows:

Where:

$$
\chi^{2}=\frac{\sum_{i=1}^{k}\left(X_{i}-N p_{i}\right)^{2}}{N p_{i}}
$$

$\mathrm{X} 2=$ chi-square

$\mathrm{Xi}=$ empirical frequency (actual)

$\mathrm{Npi}=$ theoretical frequency (expected)

The tests suggest two hypotheses - zero $\left(\mathrm{H}_{0}\right)$ and alternative $\left(\mathrm{H}_{\mathrm{A}}\right) . \mathrm{H}_{0}$ (there is no correlation between selected variables), $\mathrm{H}_{\mathrm{A}}$ (there is a correlation between selected variables). 
The assessment criterion for accepting or rejecting the hypothesis is p-value which oscillates on interval $<0.1>$. In case that the resulting $\mathrm{p}$-value is $<\alpha(0.05$ confidence interval $), \mathrm{H}_{\mathrm{A}}$ will be confirmed. Statistical calculations were carried out using R statistic program.

\section{Results}

The outcomes are ordered in the result section according to the defined hypothesis. It is possible to confirm the validity of the first hypothesis in accordance with the outcomes in the graphs 1 to 3 . The hypothesis deals with the analysis of the organizational and managerial structures in relation to the size categorization of SMESs.

It applies a departmental managerial structure in the size which is more than $70.6 \%$ in case of microenterprises (Fig. 1). $72.7 \%$ of which generates profit, $23.4 \%$ of companies have a balanced business and $3.9 \%$ of companies with a departmental managerial structure is at loss. The other organizational structures are not found in an increased quantity. It is a very surprising finding, especially in terms of linear structure.
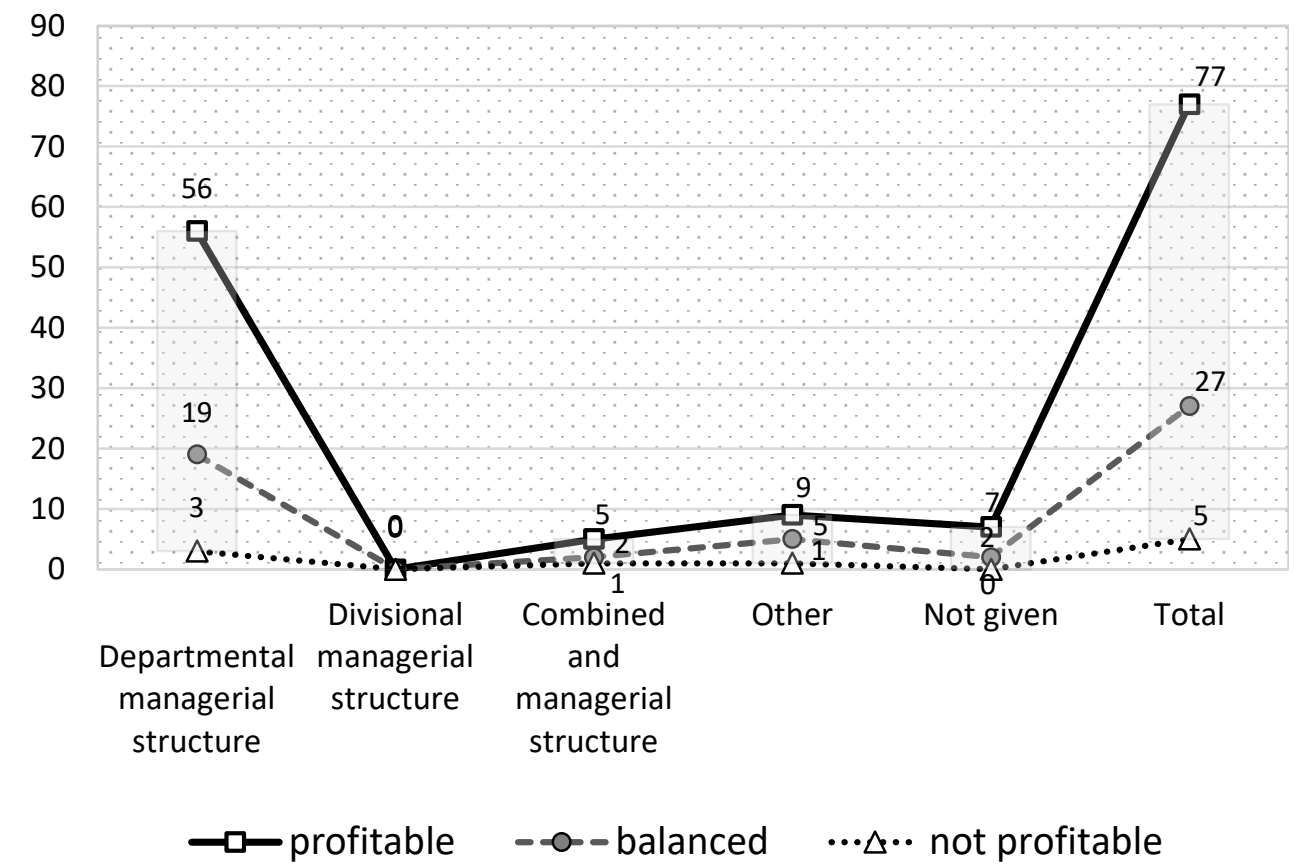

Fig. 1. The dependence of the type of organizational structure, size category, on the profitability of company in case of microenterprises

Source: Own research.

The departmental management structure is applied on small enterprises (Fig. 2) in agreement with micro-enterprises. There are namely $86.4 \%$ of enterprises. The profit in their economy is $63.6 \%, 17.4 \%$ of enterprises manage in a balanced way and at loss is $2.5 \%$ enterprises with departmental management structure. The second with a significantly lower frequency of use in business practice is the combined management structure, with $82.4 \%$ of enterprises generating profits, $11.8 \%$ operating in a balanced way and $5.9 \%$ of enterprises are at loss. Other structures such as divisional and combined structures are insignificant. 

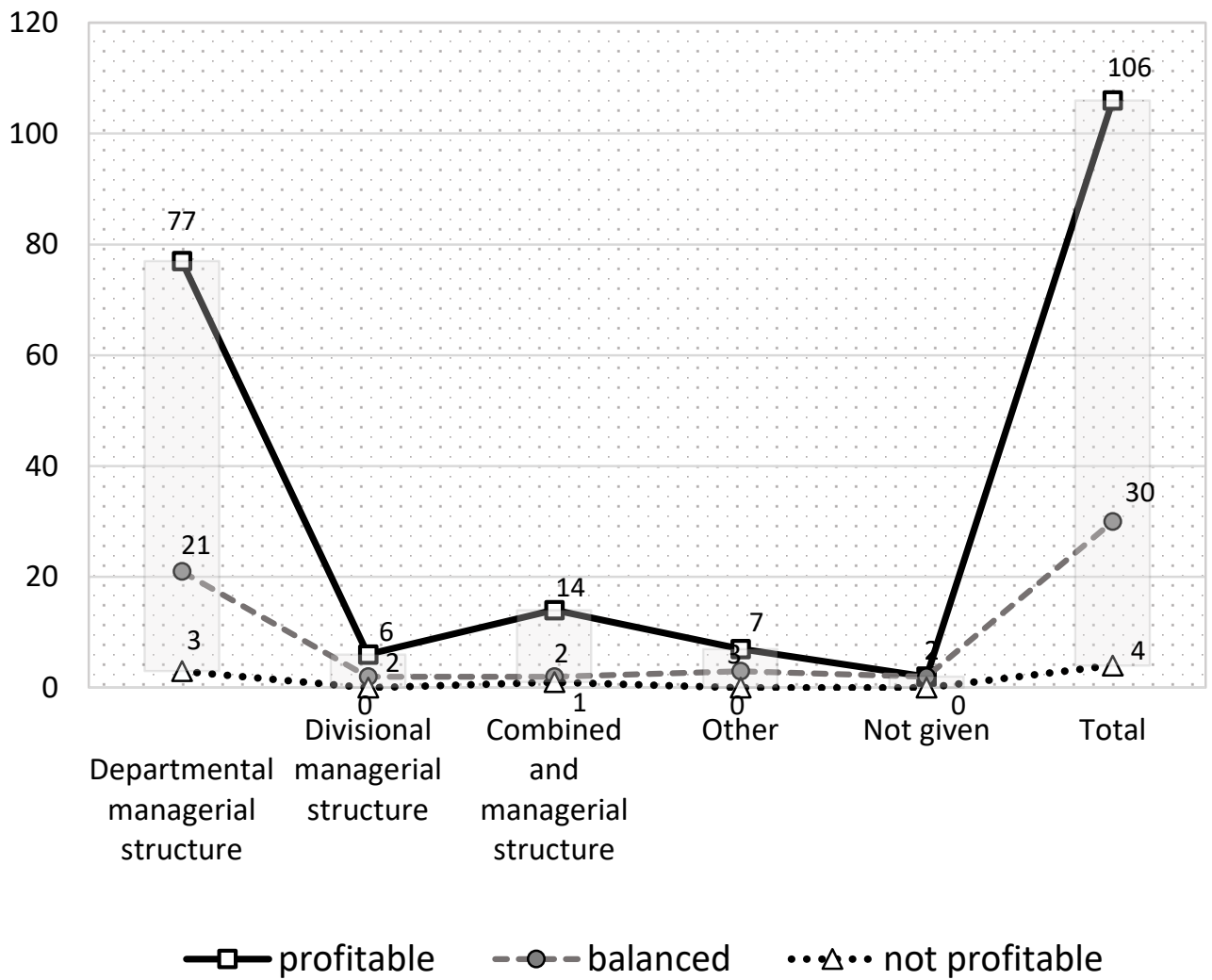

Fig. 2. The dependence of the type of organizational structure, size category, on the profitability of company in case of small enterprises

Source: Own research

Medium-sized enterprises (Fig. 3) also apply the departmental management structure the most of all, i.e. $78.9 \% .75 .3 \%$ of them generate profits, $18.6 \%$ of enterprises are in a balanced way, $6.2 \%$ show a loss. The second in terms of the frequency of use is the divisional management structure followed by the combined structure. In case of divisional structure, $66.7 \%$ of enterprises report a profit, $25 \%$ of enterprises manage their balance and $8.3 \%$ are at loss. In case of combined structure, $50 \%$ of enterprises are profitable, $30 \%$ are balanced and $20 \%$ show a loss.

In summary, departmental managerial structures predominate in all size categories of SE, most of all in micro and small enterprises, followed by medium-sized enterprises. The findings from controlled interviews have been confirmed. The transition from linear and linestaff structures to departmental structures was confirmed by the leading SMES managers. For medium-sized enterprises, the implementation of process management elements can be expected within departmental (functional) structures. However, for specialized departments, the process management process will be predominantly applied. During contact interviews, especially during structured interviews, professional and terminological illiteracy was clearly manifested. This finding is a challenge especially for educational institutions (especially relevant universities). 
The trend of transition from classical structures to departmental structures was also confirmed by statistical analysis (P.value $=0.000008287$ ). At the same time, the dependence between the type of organizational structure and the size category was proved (P.value $=$ $1,649 \mathrm{e}-06, \mathrm{~V}=0,2999)$.

It can be stated that the production and industry sector is significantly less dependent (p.value $=0.01509$ ) from the point of view of the dependence of the organizational structure on the sectoriality of the company, in contrast to the dependence indicated in the service sector $($ p.value $=0.00013)$.

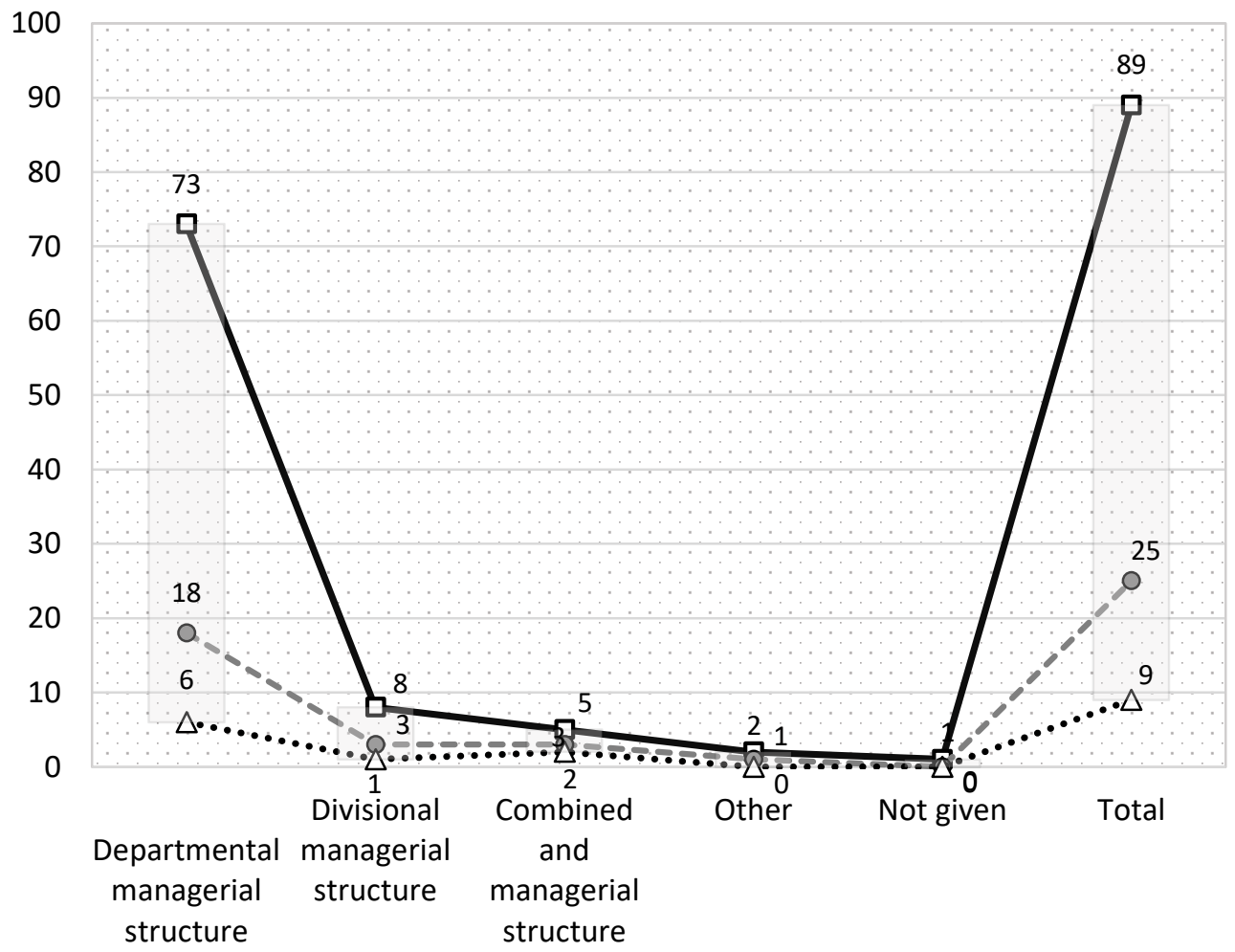

\section{$\rightarrow-$ profitable $\quad--0-$-balanced $\quad \cdots \Delta \cdots \cdot$ not profitable}

Fig. 3. The dependence of the type of organizational structure, size category, on the profitability of company in case of middle-sized enterprises

Source: Own research.

Another part of the research was focused on the analysis of the number of the levels of management depending on the size category of enterprises. Regarding the steepness of managerial structures (Fig. 4) it can be stated that micro and small enterprises dominate one level of management, medium-sized enterprises are predominantly characterized by two levels of management. The size of the company itself predetermines the number of management levels, and statistical dependence was demonstrated during the research. Especially in case of small enterprises, to a lesser extent micro enterprises, this is a consequence of gradually prevailing departmental, functional organizational and managerial 
structures. In case of medium enterprises this process has been running for several years. Functional structures reflect the changes that are currently taking place in the business sector. It is mainly the specialization of production, increasing innovative activities in these companies, introduction of information technology at the time of growing competitive pressure. Recently, the start of the digitizing of corporate processes has started to make an influence. In terms of management satisfaction with the current organizational level, $90 \%$ satisfaction was recorded.

In terms of hypothesis 2, which focuses on the number of control steps for individual size categories of SMESs, its validity can be confirmed. The prevailing share of one level of management was proved in micro enterprises. Similarly, in case of small enterprises, the gradual transformation to the departmental structure leads to an extension of the levels of management to 2 or rather 3 levels. In case of medium-sized enterprises, 3 or more levels of management are reported, i.e. in agreement with the research hypothesis.

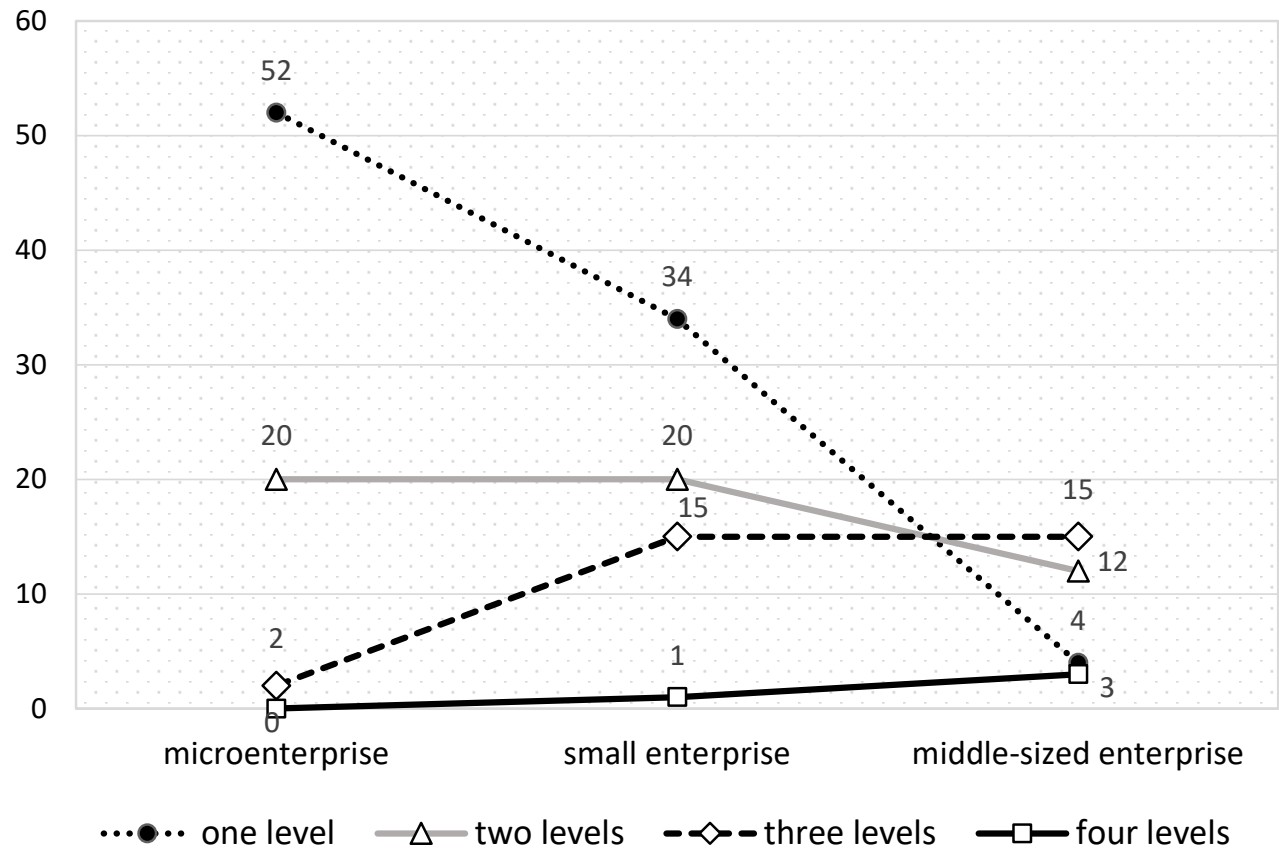

Fig. 4. The number of the levels of management in the individual size categories of SMSEs

Source: Own research.

The number of staff (scope management) on the individual the levels of management of SMESs was analyzed as a partial research question with the following outcomes:

6 or fewer employees were identified at the level of TOP management. For medium-sized companies, it is recommended to reallocate competencies and create functional units such as Sales Director, CFO or HR Director.

In the middle management position, the number of managers at the tactical level is in the range of twenty-five or less employees. Exceptionally, there is a range of twenty-five or more employees, especially in manufacturing companies.

At the operational level the degree of range is naturally the largest and reaches 30-45 employees in the size category of micro and small enterprises depending on the focus of the company. 
The analyzed numbers of employees at individual management levels were statistically tested in terms of the influence of this number on the quality of management work of managers. The obtained statistical values $(\alpha=0.05, \mathrm{p}=0.00000001239$, Chi-square $=$ 47.8964 , Number of respondents $=381, \mathrm{~V}=0.5421$ ) prove a very high degree of dependence between the number of the levels of management and the number of managers especially on TOP and tactical level. The degree of dependence is 0.5421 , which can be considered to revealing a high degree of dependence.

Based on the obtained results $(\alpha=0.05, \mathrm{p}=0.000000008665$, Chi-square $=48.6737$, Number of respondents $=153, \mathrm{~V}=0.5259)$ it can be stated ( $\mathrm{P}$ value is significantly lower than parameter $\alpha$ ), that there is a very high degree of dependence between the level of management and the size of the business. The strength of the contingency is also high: 0.5259. Microenterprises with no fixed organizational structure (subject to exceptions) were not included in the testing of this dependence.

The last tested dependency was focused on the dependence of the organizational structure type and the number of the levels of management. The results $(\alpha=0.05, p=0.719)$ show that the $\mathrm{P}$ value is 0.719 , therefore it is significantly higher than the parameter $\alpha$. On the basis of the null hypothesis, there is no dependency between the organizational structure of the company and the number of management levels.

\section{Conclusion}

The fundamental decision for all business entities for the coming period is to move towards a change in the corporate architecture. In particular, it will be the projection of a new, progressive, innovative organizational and managerial framework with a digitization aspect. If this applies in general, it is a limiting factor for the further development of SMESs. In particular, this size category will face new challenges in the near future, mainly as a result of increasing competition, permanent technological innovation, or, for example, changes in principles, forms and rules in dealing with customers. The requirements for the provision of products and services according to the specific requirements of the customer will increase. The speed of this development has allowed the emergence of new organizational structures and the abandonment of classical structures such as linear, line-staff structures, etc. in the course of the last ten years. A new bridging term of the de-structured form was created, which describes the newly created structures. The development of the use of modern production as well as information technologies and the development of the Internet mean that the potential of the dynamics of the decision-making process increases and the number of alternatives that must be identified and taken into account increases as well. The newly created organizational structures should reflect this reality and enable companies to be developed in the form of innovation and increasing flexibility.

The results of the research which are the subject of this paper are summarized in the following way:

- SMESs are undergoing intensive rebuilding of their organizational and managerial framework, but the restructuring process will be intensified if the business cycle changes.

- SMESs are already intensively approaching the transformation of their entire corporate architecture, especially organizational and managerial structures on a functional and departmental basis of organizational structures. At the same time, there is a growing need for highly qualified specialists to professionally support this organizational transformation.

- Size categorization has proved to be the decisive factor in generating the new organizational framework. The sectoriality of the company is not crucial in this case, 
but the stronger dependence between rebuilding and profitability has been proved in the field of services.

- In terms of the steepness (number of the levels of management) of organizational structures, there is a significant dependence on size categorization, less on sectoriality, which is a different outcome than that was obtained in the survey 10 years ago.

- The number of managers at individual the levels of management is highly differentiated and it is not advisable to recommend generally applicable principles. Nevertheless, it can be assumed that top managers will be subject to increasing pressure on their managerial competence, including knowledge of modern forms of management. At the tactical and operational level, demands are increasing especially in the area of human resources management.

\section{Suggestions for practice}

- It is advisable to carry out the transformation of corporate architecture in a period of economic growth.

- The change in the organization and management of the company is the result of a regular process of developing corporate structures, not a fashionable matter.

- Before the actual transformation of the organizational and managerial structure, it is necessary to process, incorporate, discuss and enforce the principles of changes in organization and management in the company and to define responsibilities of the implementation team.

- TOP management should not use the transformation of corporate architecture to deal with personal issues arising from personal antipathy towards employees.

- The existing functional elements of the corporate architecture should be preserved, while the rebuilding targets only non-functional and outdated elements.

- Every business is a living organism and a highly structured system. Therefore, its conversion must be specific and original and respect the general principles of modern management.

- One of the prerequisites for a successful transformation of business structures is to create space for an innovative process in the area of organization and management through the projection of new, innovative structures.

- The success of the proposed changes depends on the functioning communication corporate system.

- One of the limiting factors of the successful implementation of changes is to provide entire, objective and updated information for all the corporate employees because it is the only way how to secure their full support.

- Teamwork, decentralized management and flexible relations between the managerial entities should dominate in the innovative models of management.

- It is necessary to provide an objective and relevant feedback in the course of the whole transformation of corporate architecture.

- Control is an ally, not an enemy. It is necessary to create a control system including all the problematic areas which are subject to the transformation.

\section{Acknowledgements}

This article was supported by the project "Stabilization and development of SME in rural areas", reg. No. TL01000349, the TACR Éta programme. 


\section{References}

1. T. Burns, G.M. Stalker, The management of innovation. Tavistock Publications (1961)

2. J.K. Galbraith, E. Lawler, The challenge of change: organizing for competitive advantage. In: Tomorrow's organization: craft winning capabilities in a dynamic world, eds. S. A. Mohrman, J. R. Galbraith, E. E. Lawler, Jossey-Bass, San Francisco, Calif, 1-20 (1998)

3. D.K. Banner, Designing effective organizations: traditional \& transformational views. Sage: Thousand Oaks, CA (1995)

4. R. Ashkenas, D. Ulrich, T. Jick, S. Kerr, The Boundaryless organization: breaking the chains of organizational structure. Jossey-Bass: San Francisco, CA (1995)

5. G.B. Friesen, Organization design for the 21 st Century. Consulting to management, 16(3), 32-51 (2005)

6. B.J. Hodge, W.P. Anthony, L.M. Gales, Organization theory: a strategic approach, 5th ed. Prentice Hall: Upper Saddle River, New Jersey (1996)

7. J.W. O’Neill, L.L. Beauvais, R.W, Scholl, The use of organizational culture and structure to guide strategic behaviour: an information processing perspective. The Journal of Behavioural and Applied Management, 2(2), 131-150 (2001)

8. H. Mintzberg, H. Mintzberg on management: inside our strange world of organizations. Free Press: New York (1989)

9. H. Mintzberg, The structuring of organizations: a synthesis of the research. PrenticeHall: Englewood Cliffs, NJ (1979)

10. D. Katz, R.L. Kahn, The social psychology of organizations. John Wiley \& Sons: New York (1966)

11. D. Miller, Configurations of strategy and structure: towards a synthesis. In: Readings in strategic management, eds. D. Asch, C. Bowman. Macmillan Education: London (1989)

12. J. Hunter, Improving organizational performance through the use of effective elements of organizational structure. International Journal of Health Care Quality Assurance, 15(4/5), 12-21 (2002)

13. C.L. Wang, P.K. Ahmed, The informal structure: hidden energies within an organisation, Management Research Centre, Wolverhampton Business School Working Paper Series 2002, University of Wolverhampton, Telford, Shropshire (2002)

14. D. Cooper, Organizational change: From public to private sector a UK based reflective case study. Journal of American Academy of Business, 5(1/2), 474-481 (2004) 